\title{
Modernising Education: Unlearned Lessons from Frederick Taylor
}

\author{
Marina A. Shulga
}

Taras Shevchenko National University of Kyiv, Kyiv, Ukraine

\section{Galyna A. Poperechna}

Ternopil Volodymyr Hnatiuk National Pedagogical University, Ternopil, Ukraine

\section{Liubov R. Kondratiuk}

Ternopil Volodymyr Hnatiuk National Pedagogical University, Ternopil, Ukraine

\section{Halyna R. Petryshyn}

Ternopil Volodymyr Hnatiuk National Pedagogical University, Ternopil, Ukraine

\section{Oleh A. Zubchyk}

Taras Shevchenko National University of Kyiv, Kyiv, Ukraine

\begin{abstract}
Nowadays, the term "modernisation" is usually associated with the term "digitalisation", which, in its turn, is adopting semantics of the terms "modern", "progressive", "future". Frederick Taylor was one of the first scholars to face the limits of the latter and came close to a number of questions concerning their boundary indicators, content characteristics and guidelines for their establishment. Nowadays, these unexplained questions tend to disguise themselves as something "inevitable", "obvious", "insurmountable" in the educational process. The methods of an integrated approach allowed for demonstrating that the understanding of the content of the socalled "unlearned lessons" from Frederick Taylor regarding the problem of "human capacity" in terms of its mental component can help sufficiently in finding an answer to the question about the ways of developing critical thinking among the inhabitants of this space, and about the specific "trivium" and "quadrivium" for them. Therefore, it was concluded that the problem of "human capacity" is crucial for the development of the ideology of education as a system of ideas about the role and purpose of education in society, and, thus, about what is an "educated person" and how it is possible to create one today.
\end{abstract}

Linguistics and Culture Review (c) 2021.

Corresponding author: Shulga, M. A.; Email: m.shulga@tanu.pro

Manuscript submitted: 18 April 202 1, Manuscript revised: 9 June 2021, Accepted for publication: 7 July 2021 
Keywords---cultural centre, culturology, digital technologies, european culture, human capacity, information society, innovations, pedagogy, ukrainian language.

\section{Introduction}

The term "reform" means a transformation, change, or innovation in any area of public life (Busel, 2005). As for the problems of education, the term "modernisation" is still preferable, since it means changes, improvements of something that meet the requirements and challenges of the time in particular (Busel, 2005). According to experts, one of these challenges for the educational system of the 21 st century is to "allow students to connect to the Internet and find the latest information there" during the assessment of knowledge" (Shleyher, 2018). But how does the student recognise this "latest information"? The simplest answer is to consider the correlation with the information one already knows. However, there is a catch in this simple answer. Everyone, who is teaching, sooner or later faces the question of to what exact knowledge the academic discipline should contain, regardless of whether or not the participating student will continue to deal with the problems provided by the subject field of this discipline. If the volume of information is set by the hours stated in the curriculum, then its content depends a lot on the teacher's decision. For example, the issue of the explanation of the concepts and theses of the general theory of management in the course "Political Management" can be solved both by going with mandatory explanation, and by its excess, regardless of the hours defined for the study of this course. In other case, one can miss the concept of Mackinder (1919) "Heartland for Strategic purposes" in the course of "Geopolitics". Then, not only the texts of Mackinder (1919) or other authors of geopolitical concepts identified as "classics", but the entire problem of geopolitics will appear as "relic knowledge", suitable only for use in media or political discourse.

To be used is the key requirement for knowledge, the criterion of its modernity, the degree of its compliance with the challenges of the time and the requirements of the modernisation of society. This is partly inevitable since "for society in general, science enters its field of vision and begins to exist specifically in the form of new products, machines, technologies, organisational schemes, while fundamental knowledge, which is the source material of all this, is more likely to be guessed than exists as something sufficient, tangible, needed to be recognised" (Petrov, 2004). However, by focusing only on the functionality of knowledge and cultivating the habit of accepting it as the limit of knowledge, humanity seems to prevent the opportunity not just for future fundamental research but also for the basic, initial, elementary training of those who will conduct this research. Ultimately, for modernisation itself, condemning it to the scenario provided by the technology of "understanding lessons", when knowing "unique social, cultural, economic, political and religious contexts" is replaced by knowing how to use "standard, universal solutions in very different contexts" (Koppiters \& Jemerson, 2005), i.e., knowledge that is rational, technocratic and functional. However, what is the main lesson of modernisation that has to be understood? Will the answer to this question help to understand what is considered basic knowledge in the information technology era? Hence, it defines the purpose of the study. Namely, 
while considering the historical retrospect of the concept of "modernisation" and the achievements of Taylor (1911) in the studying the issue of the development of a person who meets its challenges, the goal is to reveal the nature of the problem of "human capacity" (Petrov, 2004) for the development of the ideology of education as a system of ideas about the role and purpose of education in society, and, therefore, about what is an "educated person" and how to create one.

\section{Frederick Taylor and Human Modernisation: how did the problem of "human capacity" appeared?}

This retrospective refers to the transition from agrarian societies to industrial societies, the basic feature of which is industrialisation, mechanisation and overall rationalisation of production processes. At first glance, this rationalisation is in the proposed by F. Taylor's idea of a "system of tasks", i.e., actions that must be performed in accordance with the established procedure to solve a particular production task. However, the concept of an algorithm, which prototype is Taylor's "system of tasks or lessons", assumes that the actions provided by it are possible (and, therefore, elementary) for the performer. Hence, they do not go beyond ("fit" in them) its technical and technological characteristics (if the performer is a machine), or physical, psychological and mental characteristics (if the performer is a person, including a collective one, or a person in a concept of "man-machine"). At the same time, the technical and technological parameters of the mechanic device in functional terms are derived from those previously performed with manual tools, which are replaced by machines and mechanisms (Rogers, 2002; Csibra \& Gergely, 2009). At the same time, the physical and mental actions that are necessary for solving a particular task (not necessarily production!) and perceived as "the limits of the natural abilities of human" (F. Taylor), must still be defined and studied as, for example, F. Taylor's study about their transformation into a mandatory norm for everyone.

From this standpoint, F. Taylor (1911) himself goes "by eliminating unnecessary movements and replacing slow and inefficient movements with fast ones", which are developed in the form of a "system of tasks" that are subject to mandatory and, most importantly, unquestioned and precise execution. "This task or lesson specifies in detail not only what should be done but also how it should be done, and specifies the exact amount of time spared to complete this work". However, at the same time, the lesson is "implemented" in the person so that "in no case can the worker be required to work at a pace that could be harmful to one's health" (Taylor, 1911). In other words, the working time rate (as the duration of performing a certain number of movements needed for a particular production operation) is calculated considering the limits of endurance of people who "should work as well as they can all the time" (Taylor, 1911), that is, at their limit.

Thus, the rationalisation of production processes covered by the concept of modernisation exposes the problem of "human capacity" or "human dimension" (Petrov, 1987; Petrov, 2005) as a problem of the limits of those physical and mental movements that are necessary (and, therefore, again, elementary), feasible and mandatory for everyone to learn depending on the scope of one's professional activity and the specifics of the social roles performed in general. When comprehending them, these movements are offered to the person "as something 
that does not provoke doubts and questions, as a multiplication table that prohibits the question "why?" (Petrov, 2005).

\section{Frederick Taylor and "human capacity": what is left unanswered}

The problem of "human capacity" described in this way has several components that are not fully understood by F. Taylor himself. First. If the volume of physical and metal movements to be mastered is tied rigidly to certain types of professional specialisation and, therefore, is basic only for them, or is it really basic, being the foundation for all types of labour activity, so that its elements, according to the principle of combinatorics, can give an infinite number of combinations. The F. Taylor himself is inclined to the first interpretation of baseness, defending the idea of assigning to a person with certain "limits of natural abilities" the appropriate types of work and teaching one to perform the order of movements provided by them (Delgado et al., 2019; Sanchez et al., 2019). At the same time, for F. Taylor, the "natural abilities" or "natural inclinations" themselves are something that already exists as a certain base "by default", where this or that system of "tasks or lessons" is "tested".

In other words, specialisation is based on the "natural abilities" of a person who only learns the skill to perform elementary, necessary for the production operation, where one specialises and to which one is "most adapted", movements in a particular order and at a certain speed, that is, "with the establishment of strict rules for each movement" in general (Simuth \& Sarmany-Schuller, 2012). There are many questions about this interpretation of baseness and, thus, "human capacity". For example, "natural abilities", which allow a person to be "well adapted to the production of one's work" and which should correspond to the developed "systems of tasks or lessons", which are "natural" in the sense of randomness (given by nature, given by the randomness of the origin of parents, etc.). In other case, "systems of tasks or lessons" are "natural" in the sense of the need for their preliminary development in a person as a condition for one's further professional specialisation, performed as an act of personal choice. They can also be interpreted as the natural capabilities of a person, that is, one's ability to perform physical and mental movements independently without resorting to technical aids (Taylor, 1911).

F. Taylor (1911) views human "natural abilities" as a fact that simply exists. Therefore, he is interested in the idea of "selecting one worker after another and teaching them new working skills under the guidance of a competent teacher". Taylor's programme to "learn and create" a new person, at first assumes that the student already has a certain number of "natural abilities", which allow one to be "best suited for the production of this type of work" (Taylor, 1911). Secondly, when providing by means of the tasks and lessons developed (with a stopwatch) and to be reproduced by the worker (as a result of "individual training") as a "given" "tasks and lessons", the maximum use of one's existing "default" abilities for performing the corresponding type of work, it allows for detecting the human capacity for each type of work as the "limits of human performance" (Taylor, 1911). This second aspect is undoubtedly important. However, by leaving the question of the circumstances of the appearance of a person's "natural abilities" open, F. Taylor programme initially condemns (predestines) this person to 
perform this, and not another type of activity, training one to perform it with "maximum daily productivity". For example, this anticipation of the society of the future is described by Asimov (1966) in the novel "Profession": "We can analyse the intellect, George, and determine that this person can become a decent architect, and that person can become a good carpenter".

The only difference is that F. Taylor (1911) allows the possibility of transferring (that is, not always dismissal!) an employee "to another job for which one is better suited physically or spiritually" in a situation where one "does not work properly". This can be viewed not only within the framework of discovering those "natural abilities" that make a person best suited to perform "this type of work". F. Taylor does not stipulate the possibility of reformatting already existing "natural abilities" but offers a person an algorithm for their best (in terms of individual labour productivity) use. However, he also does not specify which set of "natural abilities" should be firmly (permanently) assigned to one person, and, most importantly, whether this consolidation should happen at all. Next, there is the idea of developing the abilities that are naturally necessary for all types of human activity such an "alphabet" of human elementary mental and physical movements that can be developing elements (Petrov, 2005). The so-called "human capacity" can no longer exist in the form of randomly detected "natural abilities" of a person that undergoes selection. It has to be established. "However, no one has yet measured the volume of human capacity, knows neither threshold nor limit values, and the composition of the thesaurus, even though at the level of skills and abilities it is observable, and allows for an exhaustive description while it is in the same state of uncertainty" (Petrov, 2005).

Hence, there is the second component of the problem of "human capacity" as the basic, "maximum" number of movements (physical and mental) subjected to mandatory mastery by everyone. Is the human capacity something static, unchanging, or is it flexible, that is, can be both narrowing and expansion? What is the purpose of both? Despite the different understanding of human capacity, F. Taylor also looks for the answers to these questions. After all, when solving the problem of "developing a new human type corresponding to a new type of work and production process" (Hramshy, 1959), F. Taylor inevitably stumbles upon the limits of the human capacity of this "new type of labour", and tries to "expand" them. First of all, these are the limits of the "physical endurance" and "personal susceptibility coefficient" of a person, the achievement of the limit values of which F. Taylor observes as the "law of fatigue", which provides for the establishment of "a certain psychophysical balance outside the labour activity, which will prevent a strong physiological exhaustion of the employee" (Hramshy, 1959).

However, there are still the limits of mental capacity, that is, the human dimension of a production task that "requires a greater expenditure of mental energy" (Taylor, 1911) and must be completed quickly. The extension of such limits logically brings $F$. Taylor to gadgetisation such as a well-known example of a calculating ruler, which allowed workers to quickly solve mathematical problems related to the metal cutting process. When describing this example, F. Taylor makes a conclusion that largely determined the "fate" of the limits of a person's mental capabilities. "By means of this ruler any of these complex problems can be solved in less than half a minute by every skilled mechanic, 
whether one understands anything about mathematics or not" (Taylor, 1911). Moreover, "these calculating rulers have been in continuous daily use for a number of years by ordinary workers who have no concept of mathematics". Taylor (1911) concludes that exactly in this way in everyday life (not just in production?) complex scientific data can be used that is "beyond the experience and scope of technical training of ordinary practitioners". In other words, scientific data appears in their everyday experience creating a classic and somewhat banal situation, when knowing how to use a gadget does not mean knowing the principle ("how and why?") it works.

There is a third component of the problem of human capacity. This is the question of whether the amount of knowledge that everyone must necessarily learn as a "given" (that is, necessary, elementary) includes the knowledge of those objective, necessary and universal connections, which constitute the foundation of certain "calculating rulers" creation. Or should knowledge be just the information that something has to be done "like this and like this" by "using soand-so"? Is it not narrowing the mental component of human capacity, which contains only knowledge of the way something is used but not the way it is designed and not limited to understanding "how difficult it is to create these machines and ensure their appearance in the future" (Ortega y Gasset, 1997)? "When everything is normal, a person has nothing to do since automatic machines do everything for them, but when something fails, the only reasonable way to solve this issue is to call a specialist" (Petrov, 2005). However, what should the intellect of a person, who is always dependant on machines, come up with, if one is not a programmer, and what tasks should he solve, if one is not a specialist-adjuster? And what mental (and physical) movements can never be replaced by the machine? For example, there are the account and storage (storage) of information. Does this negate the importance of a person performing these operations independently (without relying on a machine)? What should be the tasks that require expanding the limits of human capacity, including mental capacity? The paradox is that the more "calculating rulers" a person operates with, the less knowledge of the principles of their operation and the relationships between them must be placed within the limits of the mental movements performed by the worker. The world is being comprehended using the "black box" method, rather than theoretical thinking, the original purpose of which "was to reduce the unreachable variety and unreachable diversity of being into a comprehensible problem that can be solved by comprehensible means" (Petrov, 1987).

\section{"Human capacity" and the development of critical thinking}

However, it is now generally accepted (and even fashionable somewhere) to talk about the importance of critical thinking. For example, "philosophical critical thinking skills" is the first point in the list of ten requirements that "dynamically developing companies" initially present to specialists before evaluating their actual professional knowledge and skills (Genin, 2019). However, thinking, both critical (or, more precisely, theoretical) and non-critical (or, more precisely, mundane) is contemplating about something, it has its own subject. Hence there is the fourth component of the problem of human capacity. How to define this subject matter, the participation in the creation and understanding of which 
entails the expansion of the limits of the "mental capacity of the human brain as a natural being" (Petrov, 1987). However, this definition should be not in the sense of increasing the volume of data operated by this brain but in the sense of integrating them into ways of solving social problems, considering the specific meaning of the latter. The fact that the question can be asked in this way confirms the stated "course for critical thinking".

The desired subject matter is indirectly indicated by F. Taylor and a ruler that a worker can use without having "any concept of mathematics", and a system of "tasks or lessons" that determines what "one must complete in a certain time" and is subjected to unquestioning execution by this worker. Taylor (1911) repeatedly emphasises that a person who is most flexible due to one's "natural abilities" to perform this or that type of work cannot independently develop and even comprehend the science of "labour movements and time in this special area of labour" "as due to the lack of proper education, and due to a lack of mental abilities". Since the latter is accepted as an axiom, the capacity of human movements is primarily determined by the skill of submission, which is considered not only as the automatic physical actions performed in a machinedefined order and pace (the human user) but also as a "profound moral change in the entire mental structure" (the human performer) (Taylor, 1911). Why is this so, considering that the skill of submission is really important in the "humanmachine" system? However, the dimensionality of physical movements achieved through the skill of performing a "system of tasks or lessons" and required to perform a particular job, inevitably "frees the brain for other thoughts" (Hramshy, 1959). What should be done with it? Taylor (1911) just casually dwells on this issue when he writes about the acceptability of the initiative of workers in "designing improvements, both in the field of work methods and tools" but exclusively within the prohibition to use" those types of tools and those methods, which are considered to be the best by the worker. Since this type of intellectual initiative is used by the worker "at a given level of one's mental abilities", it always turns out to be a certain deviation subjected to careful study by the administration.

H. Fayol (1917) goes further and directly points out that the intellectual initiative of the worker should be controlled and encouraged only within the limits established by respect for the authority, power, and discipline. The technical skills of a person acquired through participation in the "human-machine" system should be supplemented with the skills of social activity developed as a result of participation in the "human-human" system. This participation should be organised in such a way that the skill of subordination, which is technically necessary in the "human-machine" system, is rationalised by the person's life outside of production through "educational" events studied by Fayol (1917) and Ford (1993), so that the skill of subordination was fixed in consciousness as a belief in the unconditionality of the (in the absence of any binding to certain conditions) of the "division into rulers and subjects" (Hramshy, 1959). A person should not come across "reflections that do not contribute much to one's submission", that is, that one's mental movements are disproportionate to the question "do they proceed from the premise that humanity will be divided forever, or do they believe that this division is associated with certain conditions?" (Hramshy, 1959). As a result, the worker remained either an "grown child" who 
performs the assigned lessons (Fayol, 1917), or an automaton, "automatically fulfilling an external order" (Moskovichi, 1998).

To paraphrase Hramshy (1959), the hegemony, being born in the factory, needs for its existence outside of its maximum number of professional intermediaries in politics and ideology. However, their preparation hardly requires the development of critical thinking. After all, if thinking is not focused understanding the conditions for the emergence and existence of something but only focused on postulating this existence as something taken for granted, it can hardly be called critical. The "default" conditions are still set by a person. Their as indisputable acceptance, as well as their thoughtless denial, is not a sign of the ability to think critically at all. Moreover, if in the "human-machine" system these conditions are necessary and unavoidable (they are fixed in Taylor's "scientific organisation of work"), then in the "human-human" system this can only lead to "a scientific sanction of any observable reality with lengthy explanations of why it should be so" (Petrov, 2005). The solution is proposed by Weber (1991): “... the first task is to teach your students to recognise inconvenient facts, I mean those that are inconvenient from the point of view of their party position; and for every party position there are extremely inconvenient facts".

It turns out that the development of critical thinking involves the establishment of causal relationships between the party position as a certain way of solving political problems and its "extremely inconvenient facts" as the inevitable consequences of bringing this method of solution into action. However, it is necessary to emphasise for this question: "do they wish that there should always be rulers and subjects, or do they seek to create conditions under which the need for the existence of this division will disappear?" (Hramshy, 1959). The retention of a person's mental (and physical, in the sense of volitional) movements outside the limits of the problems defined by this question, that is, outside the limits of the problems of the "human-human" system, and turns one into an "adult child" who diligently, without unnecessary actions and, therefore, mechanically, performs a "system of tasks or lessons" developed by someone. However, the latter also means that the machine, no matter how "smart" it is, will not give an answer (or even encourage a person to search for it) to this question since it owes its mental features, like the "system of tasks or lessons", to its inventor. This, in its turn, means that "somewhere there must be men and women capable of independent thinking" (Asimov, 1966). Only the access to the "human-human" system, the element of which is the "human-machine" system, can answer the question about the consequences of robotisation.

\section{"Human capacity" and education: so, what is the basic knowledge?}

If going back to F. Taylor, the mentioned "independent thinking" no longer exists in the form of some original "natural ability" but supposes the appropriate education. Ford (1993) defines the following requirement for it: "We need people who can draw up a work plan for everything in which we see right, good and the object of our desires". Taylor (1911) does not discuss this topic much, only remarking that the purpose of such education is to inculcate "the habit of generalising and looking for laws everywhere". This will allow people who have received it to combine "many homogeneous problems" into "certain logical groups, 
and then look for some general laws or rules that they can follow for solving them" (Taylor, 1911). Whenever the previous solutions, developed by "rough practical skills" are not enough (that is, a non-standard situation will occur that does not fit into the standard of human actions), it will be relevant to know how to "search everywhere for laws" and investigate them, how to make generalisations and be guided by them. Most importantly, it will be relevant to know how to place this knowledge in the dimension of mental (mental comprehension of the decision) and physical-volitional (decision-making and implementation) movements of a person. This dimension should be unlimited in a certain sense, that is, it should allow to include a certain "unfinished text" that requires a meaningful "creative insertion" from the individual in specific actions, adding the text to meet the specific conditions of the actions" (Petrov, 2004). This "adding" is not dictated by the desire to "be different" and "do different things" but by the only critical importance for the "human-human" system of finding a non-standard solution in a non-standard situation, which is impossible without "studying the relevant laws" (Petrov, 1995).

Any activity can be represented as a certain order of movements, necessary and elementary for its implementation and dimensional to human movements, feasible for them to perform. On the contrary, the human capacity itself cannot be developed through a certain algorithm of activity. The key question is how to understand this human capacity? The meaning of the idea developed by Taylor (1911) "to learn and create this knowledgeable person" depends on this. If this is the capacity of the "natural abilities" of a person discovered as a result of selection and necessary for performing a certain type of work reduced to a "system of tasks and lessons" that dictates a certain order and pace of movements, then "learn and create" means to teach a person to make the most of these abilities to the extent that they are already established. F. Taylor writes about the obligation to teach all subordinates the fastest ways of production. However, according to his conclusion, this makes sense if the "natural abilities" of a person fit best the movements provided by a particular type of work. The same goes for Ford (1993) for whom a person should specify a job "that is more appropriate to one's physical condition and inclinations". If it is the capacity of the movements that are naturally necessary for placing in them the task of creating a "system of tasks and lessons", then "learn and create" means the naturally necessary, mandatory, and indisputable mastery of these movements as elementary ones for every person, regardless of the further professional specialisation. In the first case, the skill of submission is set by the task of accurate and unquestioning (automatic) performance of lessons-tasks, and in the second case, there is the task of joint search for a non-standard solution in a non-standard situation since the study of even the simplest law, according to Taylor (1911), suggests the collaboration between two people.

It turns out that the question of human capacity is not only a question of mental movements that are developing but not initially existing (or non-existent whichever is lucky). However, also it is about whether this capacity should initially be developed with the purpose of placing highly specialised knowledge and skills in it. Or, if there should be some universal knowledge and mental movements in the form of skills (the skill of counting, analysis, synthesis, memorisation and cognition in general), so that only further professional 
specialisation of a person is possible based on them (Lotz-Sisitka et al., 2015). (Here it is important to remember that a skill is an activity brought to automatism due to its repeatability). "The universal education that an individual receives in our cultural centre in a comprehensive school and which gives one universal skills of operations with signs, access to knowledge, continues to play the role of the initial general moment, which is the beginning of the path to specialisation" (Petrov, 2005). In this case, even in high school, a person masters the "invariant" of human activity, which is cognitive activity that is specified each time by the subject of its application and thereby specifies the acquired skill of cognition. In the case of higher education, which is responsible for specialisation, the question of human capacity is whether it should be initially "sharpened" under the functional value of knowledge (to teach how to use something) or still under their content (to teach how and, most importantly, why something is arranged this way). In the latter case, it is important to take into account that this content inevitably has a "domain of postulate datum" (Petrov, 2005), that is, its part inevitably exists in the form of "solid knowledge", in the sense of basic, elementary-necessary ones for a certain professional specialisation.

It exists in in a form "theory", if to forget that a theory is always a concept of something, a system of knowledge about something. Its understanding occurs through comprehending the internal necessary connections that are fixed by elementary "solid knowledge", basic definitions, and taught (through repetition, clarification, discussion, etc.) by academic disciplines. Understanding these connections is a long process that requires perseverance, intensity and meticulous thinking, and, therefore, cannot be replaced by simply finding the right definitions and formulations on the Internet. This search is always only an auxiliary operation, the result of which is rather not informative but general. Focusing only on digitised texts probably narrows the field of research interest? The skill of cognition becomes the skill of cognition of a certain subject area, without the theory of which the search for new knowledge is impossible (how can the new be distinguished from the already known?), as well as the invention of new "systems of things". However, in the case of knowledge about the relationship "human-human", a "given postulate" may be the thesis about the conditionality (and not the unconditionality) of the fact of "domination-subordination". Since its comprehension requires the rejection of the "vaguely felt or passively perceived in the most diverse form" (Weber, 1995) belief in the natural existence of this fact, the understanding of its conditionality is a fertile subject for the development of critical thinking for those who, for example, were not quite lucky with "universal education" in high school. The latter will inevitably stumble upon the problem of human capacity (primarily mental capacity), which is determined by the skills of "command and obey" (Petrov, 1987; Petrov, 1995), both in the situation of their rigid attachment to specific groups of individuals, and in the situation of the need for their comprehension by everyone, a situation where the skill of submission must be meaningful, that is, in fact, not be a skill.

The first situation was faced by F. Taylor, who actually analysed the system of "human-human" and for whom the one who creates a "system of tasks or lessons" is "hiding" behind a production (technical-technological) task, advocates "a profound moral change in the mental structure and habits" (performance should be regarded as a high moral quality), thereby trying to point to "the most rational 
ways to ensure the obedience of the subjects" (Hramshy, 1959). And if the rationalisation of the personal life outside the sphere of production, outside the system of "things and people" is achieved through the belief in "relations of domination-subordination between people" (Weber, 1995), established according to the "natural abilities" of everyone, then it is not the first question of critical thinking but the question of what kind of situation it is that connects "relations of domination-subordination" with certain, always different tasks, thus, requiring their different combination, different rearrangement, but does not allow them to become a universal principle of building a system of "human-human"? Thus, again, it is meaningfully, consciously performed and understood from the standpoint of the goal of the skill of submission. F. Taylor is concerned with the automatic completion of "tasks or lessons". For him, meaningfulness is an extra mental movement, along with, for example, fatigue. However, what situation requires the opposite? To paraphrase Lifshits (2003), does it require an understanding of how the mechanism works to "go" beyond its algorithm? However, to do this not in the sense of denying this algorithm but in the sense of consciously following it, that is, following it with the possibility of correction, and not executing it but making decisions.

Most importantly, whether there is a technically tangible possibility today of developing those mental human movements that can contain not just the knowledge of how to use something, but the knowledge of the user and the automaton-performer (Tarantola \& Foster, 2011; Tsoukas, 1997). In addition, there is the knowledge of how and why something is used in this way, the knowledge of the cause-and-effect relationships that are involved here, the knowledge of the performer who understands how and why something should and can be used. Is this a performer in the understanding of F. Taylor? No, since it stands out for its independent thinking but not in the sense that it arbitrarily goes against the "postulate datum" of knowledge, discards it as something unnecessary from the utilitarian and practical considerations. It stands out in the sense that through one's mental movements, the application of personal intellectual and, sometimes, volitional efforts, one comprehends the connections and laws that have been reduced to a "postulate datum" and makes them part of one's capacity. That is why it is only possible through transforming "new" knowledge into new "solid" knowledge, expanding its horizons, and, hence, the horizons of the practical application of knowledge of these connections and laws. One might argue that "... knowledge of the laws of causation cannot be the goal and is only a means of research" (Weber, 1995). However, the establishment of causal relations, i.e., "knowledge of the laws of causation", is not a naturally existing but an acquired and developed mental movement. It is research.

\section{"Human capacity" and information technology}

Is it worth knowing the principle of the computer at all, if S. Jobs, for example, believed that people should not know this (Sheff, 1985)? Probably, it is worth knowing since the information, according to Wiener (1958), is just a "content designation", and computers operate on this designation as a set of digits (1 and 0 ) in the binary system. Besides, all the information (not just computer) technologies that everyone uses and that everyone knows about are based on this system. The system that back in 1837 allowed for building the first mechanical 
computer on "logic gates" (devices that produce the result of a Boolean operation from the data (signals) entered into it. It allowed for recording (storing) information in the form of a set of 0 and 1 (black and white dots, magnetised and non-magnetised areas, depressions and protrusions, etc.). Thus, it could be done due to the ability to set one of the possible physical states to a specific section (volume) of the "carrier" and the ability to "count" (measure, determine) this condition. The read state of the media section is either 1 or 0 . The signal (or its absence) is applied to one of the inputs of the logic gate. The signal from another section is sent to another input. The presence or absence of a signal at the output of a logic gate depends on the presence or absence of signals at its inputs (this is called the logic of the valve operation). Valves with their inputs and outputs can be connected to each other in a certain designed order. Thus, there is a logical scheme with a specific architecture (Farrow, 2019; Stephan \& Henneberg, 2001). Valve inputs that are not connected to other valves are intended for entering information. Valve outputs that are not connected to other valves designed for output. Depending on the architecture of connections, different circuits will have different output signals with the same input signals. By combining different circuits into blocks, one can get different algorithms for processing input signals.

One should assemble a circuit from logic gates, which is used as transistors since they need electricity to work. One sends signals to the inputs in the form of alternating DC pulses (these will be 0 and 1) at a speed of 1 billion signals per second for each entrance. From the outputs of the circuit, one will remove a different sequence of signals and send them in their directions, meaning to the video card, sound card, and hard disk. S. Jobs said that computer follows very clear instructions such as "take this number, add it to that one, output the result there..." (Sheff, 1985). However, it is worth noting that this step is 1 million times faster for the computer. The result is truly magical (Sheff, 1985). It truly is since, for example, on an area of 289 square meters $(17 \times 17 \mathrm{~mm}$.) one can place about 3 billion logic gates (transistors). It increases with moving further. The number of layers increases, and the geometric dimensions of the data storages decrease.

Miniaturisation, which has never been able to spread to books, returns to the problem of human capacity within the limits of the mental component of which one can put something (in this particular case, the principle of the computer) not in the form of representation, sensation, contemplation but only in the form of understanding (Pagoropoulos et al., 2017; Li et al., 2020). That is provided by the fact that the ability to perform the appropriate mental movements is developed (the "Ford School" with its principle of clarity in training and "the application of specific tasks of the factory" will not help here). And if not? Does it mean that all that remains is "allow students to connect to the Internet and find the most upto-date information there"? Is this in the sense of recently digitised information? And if the student does not have the appropriate means of connecting (these "natural abilities")? And if the available connection tool does not have the necessary software needed to process the most up-to-date information? And if they find themselves to be the users of the social network MySpace, which for a decade and a half has been used by musicians around the world to publish their works and which recently officially admitted that "it has irretrievably lost" almost all of these works? It lost all user content from 2003 to 2015, which is fifty million songs. And if the information, without which it will be impossible to manage a 
nuclear power plant, is deleted? After all, how does it differ from erased songs? They are all the same 0 and 1.

Again, the ease of handling a computer, the speed of access to information as a "designation of content" does not cancel (and does not replace) the task of recognising this content through comprehension and understanding. However, this task somehow recedes more into the "background" since this type of comprehension is long and it is much easier to turn on the computer and read the next "final sum of words" from the screen. Moreover, the information "found" on the Internet often does not serve as an impetus for the subsequent movement but is perceived as a "complete information base", the only true and only complete one. When academic disciplines are compressed to a logical " 0 ", this also probably reduces the mental component of human capacity to machine functions of reading and reproducing (classification by specified criteria, search by specified keywords, etc.), that is, to operating with signs (regardless of what media they are placed on) without understanding the content that these signs contain (Here it is worth mentioning the famous thought experiment of Searle (1990) "The Chinese Room").

It happens before the ability to comprehend a certain final text without developing the ability to understand the subject that is reflected in this text. And if, again, paper media will be of a low demand and the information on electronic devices will either disappear, or will not be transferred there at all? Or will it be postponed but with a suggestion of a different interpretation? (Here, it could be mention that the "understanding" of the law of universal gravitation, retold by one of the heroes of the Heinlein (2014) "The Stepsons of the Universe", and the interpretation of the word "intellectual" defended by the antipode of the main character in Bradbury (1953) "Fahrenheit 451", and "educational tapes" in Asimov (1966). "Profession", which "teach too much and too easily" but do not teach "to learn further independently", and which were actually patented in the mentioned "Ford School"). Will we eventually end up in situations described by prominent writers of science fiction? For example: "I want you to teach me to understand what I read" (Bradbury, 1953); "I tried to remember, but if I look away, I forget everything" (Bradbury, 1953); "do you think that if you are taught to read and write, you already know everything?" (Heinlein, 2014); one should only be interested in "how something is done", and not in "what for and why" and, as a result, "why learn anything other than the ability to press buttons?" (Bradbury, 1953). The latter situation is particularly significant in modern society, which is commonly called the information society.

\section{Conclusion}

To conclude, F. Taylor defines the problem of human capacity as an issue of elementary physical and mental movements that must be mastered by everyone, and solves it in favour of movements that are mandatory for becoming a skill from the standpoint of the "human-machine" system. Moreover, F. Taylor compresses these movements to the set of tasks or lessons, and they, in their turn, are reduced to the skill of submission, which consolidation should contribute to the appropriate organisation of human life outside of production. Hence, there is the arguments about the importance of a profound moral change in the entire mental 
structure and habits. The skill of submission as the unquestioning fulfilment of prescribed "tasks or lessons" by a person, subordinates one's life in the "humanmachine" system to the "on - off" rhythm. However, nowadays this rhythm becomes universal since one machine, the computer, has passed into "universal distribution" and has become an attribute of everyone's life. Why remember something, know something, learn something, if at any time you can get the necessary information just by turning on your computer and connecting to the Internet?

The process of cognition will always be tied to a person as its only subject. And this is the main lesson of F. Taylor. After all, the system of tasks or lessons is also created by a human. This means that the process of creation depends on the limits and one's (and not just the final performer of the created "tasks or lessons") mental capacity, on what mental elementary movements were learned. That is why the question of human capacity as a question of the necessary-mandatory for the mastery by everyone (why everyone and whether it has to be everyone are important questions that require research in the context of the problem of human capacity) mental movement can be considered key to the ideology of education, if the ideology is understood by including the principles that manage relations within social production. In this case, it is education as the sphere of production of people who meet the challenges of the time. Without an answer to this question, the challenges of the time threaten to turn students not so much into educated people as into "stepsons of the Universe".

\section{References}

Asimov, I. (1966). Profession. Don, 1, 73-115.

Bradbury, R. (1953). Fahrenheit 451 (New York: Ballantine, 1981). Originally published in.

Busel, V. T. (2005). Velykyi tlumachnyi slovnyk suchasnoi ukrainskoi movy [Great explanatory dictionary of modern Ukrainian language]. Kyiv: Perun.

Csibra, G., \& Gergely, G. (2009). Natural pedagogy. Trends in cognitive sciences, 13(4), 148-153. https://doi.org/10.1016/j.tics.2009.01.005

Delgado, M. A. C., Delgado, R. I. Z., Palma, R. P., \& Moya, M. E. (2019). Dyscalculia and pedagogical intervention. International Research Journal of Management, IT and Social Sciences, 6(5), 95-100.

Farrow, E. (2019). To augment human capacity-artificial intelligence evolution through causal layered analysis. Futures, 108, 61-71. https://doi.org/10.1016/j.futures.2019.02.022

Fayol, H. (1917). Administration Industrielle et Générale, Paris. - Dunod at Pinat.

Ford, H. (1993). My life, my achievements. Kyiv: Graylyik.

Genin, V. (2019). Global problems of higher education: New goals, objectives, and innovative solutions for the training of specialists in business administration and public administration in the USA.

Heinlein, R. A. (2014). Orphans of the Sky. Hachette UK.

Hramshy, A. (1959). Selected works in three volumes. Moscow: Izdatelstvo inostrannoy literatury.

Hysa, O. A., Stepaniuk, I. V., Vaniuha, L. S., Zhorniak, B. Y., \& Rehulich, I. V. (2021). Jagiellonianism in Poland and Ukraine as a factor of university 
education and a cultural and historical phenomenon. Linguistics and Culture Review, 5(S2), 68-79. https://doi.org/10.37028/lingcure.v5nS2.1331

Koppiters, B., \& Jemerson, M. (2005). Europeanisation and conflict resolution: specific studies of the European periphery. Moscow: Ves mir.

Li, Y., Dai, J., \& Cui, L. (2020). The impact of digital technologies on economic and environmental performance in the context of industry 4.0: A moderated mediation model. International Journal of Production Economics, 229, 107777. https://doi.org/10.1016/j.ijpe.2020.107777

Lifshits, M. A. (2003). Dialogue with Evald Ilyenkov (the problem of the ideal). Moscow, Progress-Tradition Publ.

Lotz-Sisitka, H., Wals, A. E., Kronlid, D., \& McGarry, D. (2015). Transformative, transgressive social learning: Rethinking higher education pedagogy in times of systemic global dysfunction. Current Opinion in Environmental Sustainability, 16, 73-80. https://doi.org/10.1016/j.cosust.2015.07.018

Mackinder, H. J. (1919). Democratic ideals and reality: A study in the politics of reconstruction (Vol. 46399). H. Holt.

Moskovichi, S. (1998). Vek tolp. Istoricheskij traktat po psihologii mass [The Age of Crowds. Historical Essay on Psychology of Masses]. Moscow.

Ortega y Gasset, J. (1997). Rise of the Masses. In: A.M. Rutkevich (Ed.), Selected Works. Moscow: Ves Mir.

Pagoropoulos, A., Pigosso, D. C., \& McAloone, T. C. (2017). The emergent role of digital technologies in the Circular Economy: A review. Procedia CIRP, 64, 1924. https://doi.org/10.1016/j.procir.2017.02.047

Petrov, M. K. (1987). Penteconter. In the first class of the European school of thoughts. Questions of history of science and technology, (3), 100-109.

Petrov, M. K. (1995). Pirates of the Aegean Sea and personality. M. ROSSPEN..

Petrov, M. K. (2004). Language, sign, culture (pp: 328). Moscow: URSS.

Petrov, M. K. (2005). A Region as an Object of Systematic Study. Yuzhnorossiiskoe obozrenie TsSRIP IPPK RGU i ISPI RAN.

Rogers, E. M. (2002). Diffusion of preventive innovations. Addictive behaviors, 27(6), 989-993. https://doi.org/10.1016/S0306-4603(02)00300-3

Sanchez, P. K. M., Lopez, C. G. N., Lopez, M. M. L., \& Figueroa, Y. G. M. (2019). Learning problems: pedagogical intervention. International Research Journal of Engineering, IT and Scientific Research, 5(6), 25-32.

Searle, J. R. (1990). Is the brain's mind a computer program?. Scientific American, 262(1), 25-31.

Sheff, D. (1985). Playboy Interview: Steve Jobs. Playboy, February.

Shleyher, A. (2018). The best class in the world: how to create an educational system of the 21 st century. Lviv: Litopys.

Simuth, J., \& Sarmany-Schuller, I. (2012). Principles for e-pedagogy. ProcediaSocial and Behavioral Sciences, 46, 4454-4456. https://doi.org/10.1016/j.sbspro.2012.06.274

Stephan, C. N., \& Henneberg, M. (2001). Medicine may be reducing the human capacity to survive. Medical hypotheses, 57(5), 633-637. https://doi.org/10.1054/mehy.2001.1431

Suleymanli, M. (2021). Modernization and culture in Azerbaijan: second half of the XIX century: beginning of the XX century. Linguistics and Culture Review, 5(S1), 125-138. https://doi.org/10.37028/lingcure.v5nS1.1324

Tarantola, D., \& Foster, S. O. (2011). From smallpox eradication to contemporary global health initiatives: enhancing human capacity towards a global public 
health

goal. Vaccine, 29,

D135-D140.

https://doi.org/10.1016/j.vaccine.2011.07.027

Taylor, F. W. (1911). Principles and methods of scientific management. Journal of Accountancy, 12(2), 117-124.

Tsoukas, H. (1997). The tyranny of light: The temptations and the paradoxes of the information society. Futures, 29(9), 827-843. https://doi.org/10.1016/S0016-3287(97)00035-9

Weber, M. (1991). Self-consciousness of the European culture of the twentieth century: Thinkers and writers of the West about the place of culture in modern society. Moscow: Politizdat.

Weber, M. (1995). "Objectivity" of knowledge in the field of social sciences and social policy. In: Culturology. XX century. Moscow: Yurist (p. 557).

Wiener, N. (1958). Cybernetics and Society. Moscow: Izdatelstvo inostrannoy literaturyi. 